\title{
Reagent free electrochemical-based detection of silver ions at interdigitated microelectrodes using in-situ $\mathrm{pH}$ control
}

\author{
Luiza A. Wasiewska ${ }^{\mathrm{a}, \mathrm{b}}$, Ian Seymour ${ }^{\mathrm{a}}$, Bernardo Patella ${ }^{\mathrm{c}}$, Rosalinda Inguanta ${ }^{\mathrm{c}}$, \\ Catherine M. Burgess $^{\mathrm{b}}$, Geraldine Duffy ${ }^{\mathrm{b}}$, Alan O'Riordan ${ }^{\mathrm{a}}{ }^{*}$ \\ ${ }^{a}$ Nanotechnology Group, Tyndall National Institute - University College Cork, Dyke Parade, Cork, Ireland \\ ${ }^{\mathrm{b}}$ Food Safety Department, Teagasc Food Research Centre, Ashtown, Dublin, Ireland \\ ${ }^{\mathrm{c}}$ Laboratorio di Chimica Fisica Applicata, Dipartimento dell'Innovazione Industriale e Digitale Ingegneria Chimica Gestionale Informatica Meccanica, Università di \\ Palermo, Viale delle Scienze, Palermo, Italy
}

\section{A R T I C L E I N F O}

\section{Keywords:}

Silver ions

Tap water

Square wave voltammetry

Local $\mathrm{pH}$ control

Interdigitated gold microband electrodes

\begin{abstract}
A B S T R A C T
Herein we report on the development of an electrochemical sensor for silver ions detection in tap water using anodic sweep voltammetry with in-situ $\mathrm{pH}$ control; enabled by closely spaced interdigitated electrode arrays. The in-situ $\mathrm{pH}$ control approach allowed the $\mathrm{pH}$ of a test solution to be tailored to $\mathrm{pH} 3$ (experimentally determined as the optimal $\mathrm{pH}$ ) by applying $1.65 \mathrm{~V}$ to a protonator electrode with the subsequent production of protons, arising from water electrolysis, dropping the local $\mathrm{pH}$ value. Using this approach, an initial proof-of-concept study for silver detection in sodium acetate was undertaken where $1.25 \mathrm{~V}$ was applied during deposition (to compensate for oxygen production) and $1.65 \mathrm{~V}$ during stripping. Using these conditions, calibration between 0.2 and $10 \mu \mathrm{M}$ was established with the silver stripping peak $\sim 0.3 \mathrm{~V}$. The calculated limit of detection was $13 \mathrm{nM}$. For the final application in tap water, $1.65 \mathrm{~V}$ was applied to a protonator electrode for both deposition and stripping of silver. The chloride ions, present in tap water (as a consequence of adding chlorine during the disinfection process) facilitated silver detection and caused the striping peak to shift catholically to $\sim 0.2 \mathrm{~V}$. The combination of the complexation of silver ions with chloride and in-situ $\mathrm{pH}$ control resulted in a linear calibration range between 0.25 and $2 \mu \mathrm{M}$ in tap water and a calculated limit of detection of $106 \mathrm{nM}$ without the need to add acid or supporting electrolytes.
\end{abstract}

\section{Introduction}

Silver nanoparticles, due to their antimicrobial effect and physical properties, have become ubiquitous in a wide variety of products ranging from electronic \& medical devices, textiles, cosmetics through to home disinfectants [1]. Their increased use in consumer products has, however, resulted in their unwanted release into the environment, particularly into water sources [2]. It is purported that the antimicrobial activity of silver nanoparticles involves the slow release of silver ions into the solution, which is the most toxic form of silver [3]. Silver toxicity to aquatic life has been well documented, while bioaccumulation in humans may lead to a disease called argyria [4]. Despite the lack of robust data on silver toxicity in humans, the World Health Organisation (WHO) [5] have suggested $0.1 \mathrm{mg} / \mathrm{L}(\sim 0.93 \mu \mathrm{M})$ as the upper limit for silver in drinking water. Accordingly, in recent Drinking Water Standards and Health Advisories Tables, the United
States Environmental Protection Agency (EPA) [6] have proposed the same permissible $(0.1 \mathrm{mg} / \mathrm{L})$ concentration of silver in drinking water. There is therefore a need, on health grounds, for rapid methods to monitor silver concentrations in drinking water.

Several instrumental and non-instrumental methods for the detection of silver in aqueous solutions have been described to date. These include atomic absorbance spectroscopy [7], colorimetric [8], fluorescent [9], and electrochemical methods [10]. Recently, much attention has focused on electrochemistry as a detection technique, due to its low cost, suitability to device miniaturization \& portability, as well as simplicity of use, crucial for point-of-use application [11-14]. One of the most often used electrochemical technique for silver detection is anodic sweep voltammetry (ASV) which comprises two major steps pre-concentration of the metal at an electrode followed by its oxidation by sweeping the potential around its oxidation potential. Several authors have developed sensors for silver detection with ASV using a wide

\footnotetext{
* Corresponding author.

E-mail address: alan.oriordan@tyndall.ie (A. O’Riordan).
} 
range modified and non-modified of electrode materials, such as boron-doped diamond [15], gallium nitrate [16], graphite felt [17] or carbon paste [18]. Typically, carbon paste or glassy carbon electrodes modified with a variety of different ligands, such as N,NO-bis (2-hydroxybenzylidene)-2,20(aminophenylthio) ethane [19]; CNT and (E)-4-(2-hydroxyethylimino) pentan-2-one (EHPO) [20]; phenylthiourea-functionalized high ordered nanoporous silica gel [21] or 8-Mercaptoquinoline [22], offered very low limits of detection, which addresses one of the major challenge in development of sensor for silver detection. However, the modification of the electrodes is laborious, of variable quality and reproducibility, and may be expensive. The application of nano- and micro-electrodes for electrochemical analysis has offered significant advantages such as increased signal-to-noise ratio, higher current density and therefore higher sensitivity without the need for electrode's modification [23,24]. For instance, the study conducted by Sidambaram and Colleran [25] applied gold and platinum nanoelectrodes for the detection of silver ions. However, they have conducted their experiments in chloride-free buffer stating that the presence of chloride ions greatly affects reproducibility of the sensor.

Another challenge in development of silver sensor is a typical need for $\mathrm{pH}$ modification before the measurements. The $\mathrm{pH}$ of a sample solution is one of the crucial parameters in metal detection using ASV and its optimisation during deposition, and stripping is one of the first steps in sensor development [26-28]. The optimal concentration of $\mathrm{H}^{+}$ions can delay side reactions, e.g., a metal's complexation with other species and thus increase the availability of the metal for electrodeposition and consequently, the final measured signal [29]. However, in many deployment scenarios for real-time silver detection, $\mathrm{pH}$ adjustment of a solution prior to a measurement remains unfeasible. The optimal $\mathrm{pH}$ for silver detection is strongly affected by electrode material composition, type of ligand, modification process, and the supporting electrolyte and has been reported by other authors to vary between $\mathrm{pH} 1.1$ [30] and 9.5 $[19,31]$; depending on the parameters used. Tap water $\mathrm{pH}$ typically varies between 6.5 and 8.5, and thus prior to detection in these samples, reagents such as nitric acid [21] or acetic acid [32] are usually added. Ideally, an electrochemical-based sensor for tap water should allow for detection within this $\mathrm{pH}$ range without manual adjustment. Mineral acids are usually used to adjust the $\mathrm{pH}$. However, more recently, an electrochemical based in-situ $\mathrm{pH}$ adjustment method, using a boron-doped ring disc electrode system, was demonstrated for the detection of mercury in water [29]. This approach was based on electrochemically driven decomposition of water achieved by applying a sufficiently high oxidising potential to the ring electrode. During this process, hydrogen ions were anodically produced at the ring electrode which diffused to and caused acidification of the solution near the 'sensing' disk electrode.

In the current study, we extended this approach by developing solidstate sensors on silicon chip substrates that incorporated interdigitated microelectrodes for the detection of silver ions in sodium acetate and tap water. Each sensor comprised two interdigitated electrodes arrays (IDAs) and in our approach, the platinum protonator IDA was used to electro-generate $\mathrm{H}^{+}$ions while the gold working IDA was used to detect the silver (I) ions. By applying a constant potential to a pronator IDA, the in-situ $\mathrm{pH}$ surrounding an electrode could be easily tailored within a range of $\mathrm{pH} 2-10$. The optimisation of the technique and the proof-ofconcept experiments were performed in sodium acetate while the final application was done in tap water.

\section{Material and methods}

\subsection{Reagents}

Sodium acetate, silver nitrate, nitric acid, ferrocenecarboxylic acid (FCA), and PBS tablets were obtained from Sigma Aldrich, Ireland. Hydrogen dinitrosulphatoplatinate(II) (DNS) platinum plating solution was obtained from Johnston Matthey chemical products. $50 \mathrm{~mL}$ stock solution of $20 \mathrm{mM}$ silver nitrate was prepared by diluting it with ultrapure Milli-Q water (18.2 M $\Omega . c m$, Milli-Q) and stored in a fridge at 4 ${ }^{\circ} \mathrm{C}$. Silver samples were made by diluting the stock solution with the selected electrolyte (sodium acetate or tap water) before each measurement. Sodium acetate was prepared by diluting it to the desired concentration $(0.01 \mathrm{M})$ with ultra-pure Milli-Q water $(18.2 \mathrm{M} \Omega . \mathrm{cm}$, Milli-Q). If needed, $1 \mathrm{M}$ nitric acid was added drop-wise until the desired $\mathrm{pH}$ was obtained. Tap water used for the experiments was not treated prior to use.

\subsection{Apparatus}

All the electrochemical measurements were undertaken using a $\mathrm{CHI}$ 920 potentiostat with a bipotentiostat function. A three electrode configuration was used for the silver detection in acidified solutions where gold interdigitated microband electrode (working IDA) was employed as a working electrode, gold on-chip wire as a counter electrode, and an external $\mathrm{Ag} / \mathrm{AgCl}$ as a reference electrode. An additional platinum protonator interdigitated electrode (protonator IDA) was used in a four electrode configuration for the experiments employing in-situ electrochemical $\mathrm{pH}$ control.

\subsection{Silicon chips fabrication}

Interdigitated electrodes array (IDA) at silicon chips were designed and fabricated for silver detection. Fabrication of the chips was similar to those described by Wahl et al. [23]. Briefly, gold microband electrodes were fabricated on four-inch silicon wafer substrates bearing a $\sim 300 \mathrm{~nm}$ layer of thermally grown silicon dioxide; see Fig. S1. IDAs were first fabricated using a combination of optical lithography, metal evaporation (Ti $5 \mathrm{~nm} / \mathrm{Au} 50 \mathrm{~nm}$ Temescal FC-2000 E-beam evaporator) and lift-off techniques to yield well-defined, stacked metallic (Ti/Au) microband ( $1 \mu \mathrm{m}$ width, $50 \mathrm{~nm}$ height, $80 \mu \mathrm{m}$ length) structures. Each chip comprised six independent sensors. A second optical lithographic and metal deposition (Ti $10 \mathrm{~nm} / \mathrm{Au} 100 \mathrm{~nm}$ ) process was then undertaken to define a MicroSD pin-out, interconnection tracks, as well as counter electrodes ( $500 \mu \mathrm{m}$ wide $\mathrm{x} 10 \mathrm{~mm}$ long). In this work, an on-chip microSD style electrical pin-out was included to permit facile electrical connection to external electronics. In this manner, chips could be easily swapped in and out with the potentiostat, enabling rapid analysis of multiple samples. A custom-built cell was designed and fabricated so that when screwed together, the microSD primary contact pads protruded out of the holder to allow connection with a PCB mounted microSD port. As platinum is known to catalyse water electrolysis, following fabrication, platinum was electrodeposited on a protonator IDA to promote proton flux production at lower over-potentials. The platinum deposition was undertaken by immersing a chip with an electrical connection made to one interdigitated comb in the commercial DNS plating solution and applying $-0.5 \mathrm{~V}$ ( $\mathrm{vs} \mathrm{Ag} / \mathrm{AgCl}$ ) for five seconds.

\subsection{Electrode characterisation}

Following fabrication, optical microscopy was employed to identify any obvious defects or faults, with faulty chips being discarded. Chips were cleaned by immersion and sonication for ten minutes, first in ethanol, then in de-ionized water, and dried in a flow of nitrogen. The electrochemical characterisation was undertaken in a Faraday cage using a CHI 920 potentiostat. Cyclic voltammograms (CV) were performed from $0 \mathrm{~V}$ to $0.6 \mathrm{~V}$ at $50 \mathrm{mV} / \mathrm{s}$ in $1 \mathrm{mM}$ FCA. Generator-collector scans, where the protonator IDA were held at $0 \mathrm{~V}$ and the working IDA swept as above, were also undertaken. All electrochemical characterisation measurements were recorded versus an $\mathrm{Ag} / \mathrm{AgCl}$ external reference electrode. 


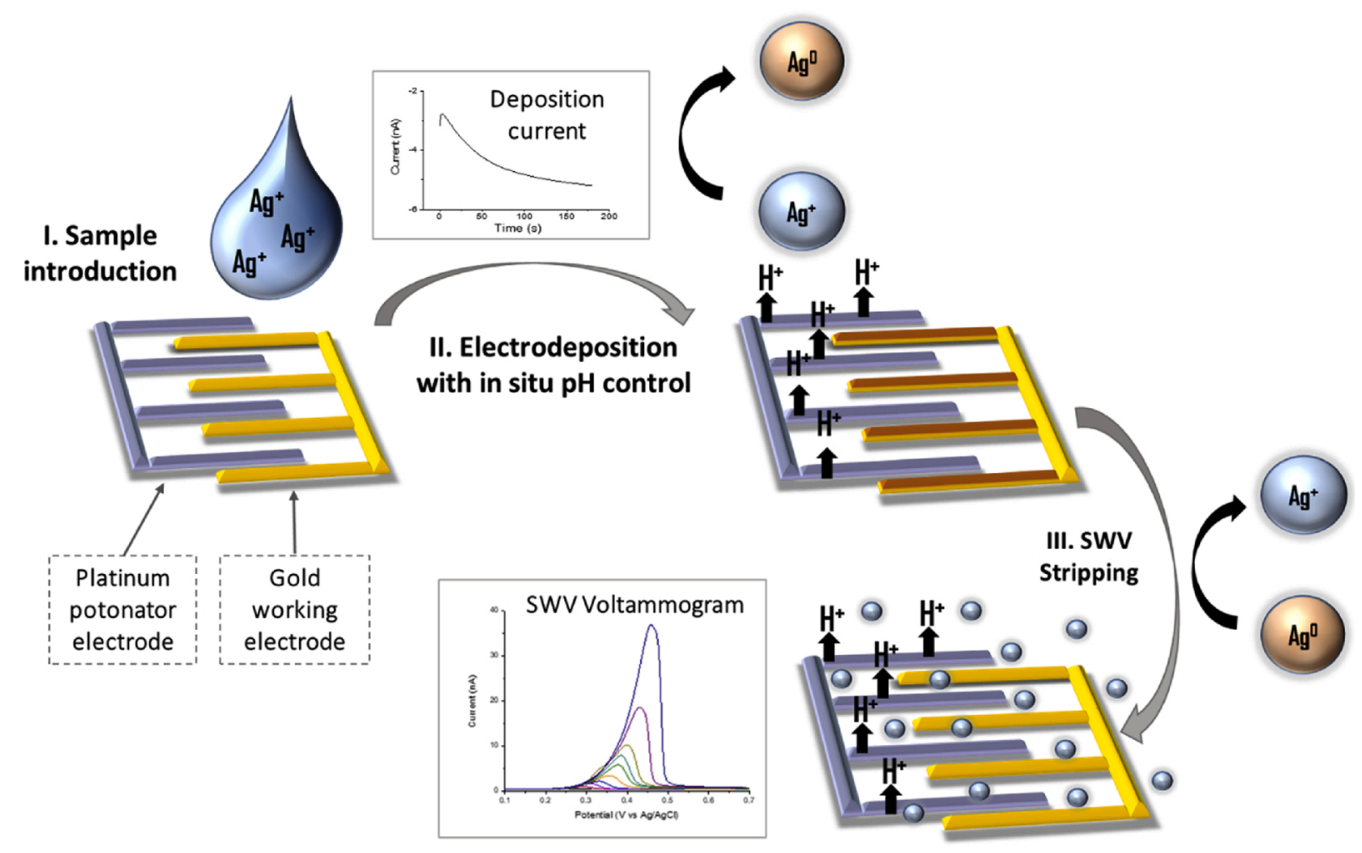

Fig. 1. Scheme showing the silver detection process on an interdigitated microband electrode.

\subsection{Silver detection method in acidic media}

Electrochemical detection of silver was undertaken as shown schematically in Fig. 1 (i) First, $500 \mu \mathrm{L}$ of test solution was introduced onto a sensor chip. (ii) Silver ions were then electrodeposited to form bulk silver on the surface of gold working IDA according to Eq. 1 .

$A g^{+}+e^{-} \rightarrow A g^{0}$ (iii) Finally, square wave stripping voltammetry (SWV) was used to strip the silver from the underlying gold working IDA (see Eq. 2), with the corresponding oxidation peak height current proportional to a concentration of silver pre-deposited on a sensor.

$A g^{0}-e^{-} \rightarrow A g^{+}$

In brief, the method comprised the following steps: a) A $500 \mu \mathrm{L}$
A

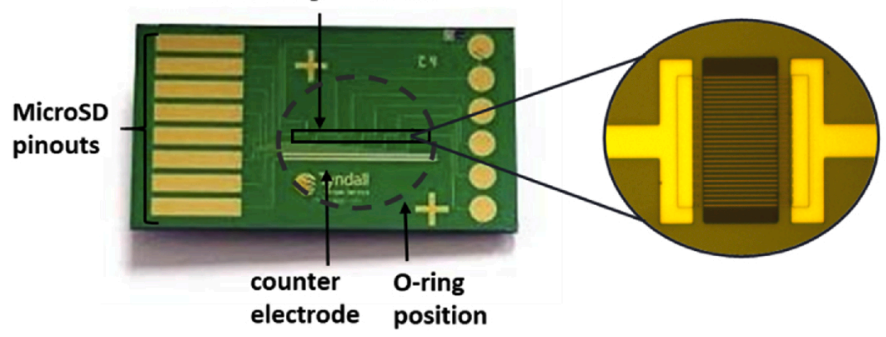

B

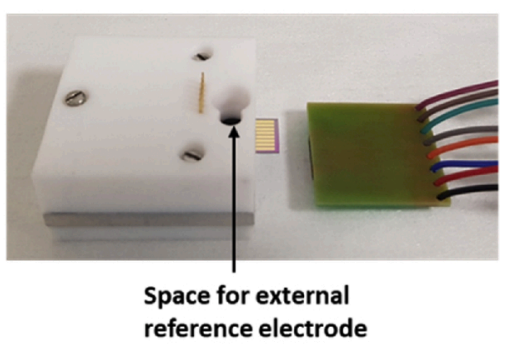

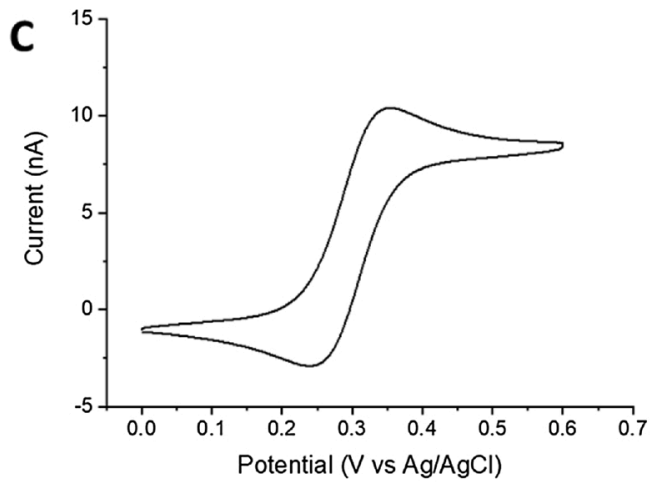

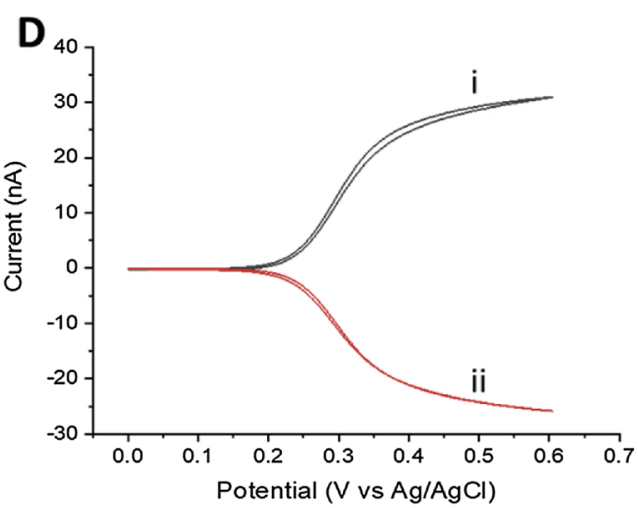

Fig. 2. (A) Picture of a fully integrated silicon sensor chip and optical micrograph of a sensor electrode comprising two interdigitated electrode arrays. The central dark rectangle region is the passivation window opening. (B) Electrochemical cell with sensor chip and a PCB microSD connector. (C) Typical cyclic voltammogram in $1 \mathrm{mM} \mathrm{FCA}$ in $10 \mathrm{mM}$ PBS measured at an interdigitated electrode comb. (D) CVs at the generator and collector IDAs of $1 \mathrm{mM}$ FCA in $10 \mathrm{mM}$ PBS at a scan rate of 50 $\mathrm{mV} / \mathrm{s}$. The generator IDA (i) was cycled between $0 \mathrm{~V}$ and $0.6 \mathrm{~V}(\mathrm{vs} \mathrm{Ag} / \mathrm{AgCl}$ ) while the collector IDA (ii) was held at $0 \mathrm{~V}$. 



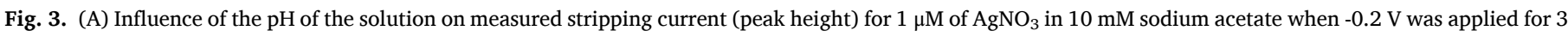

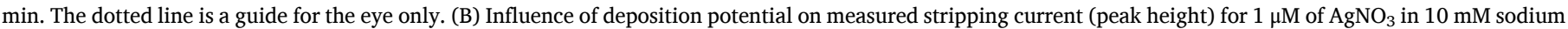

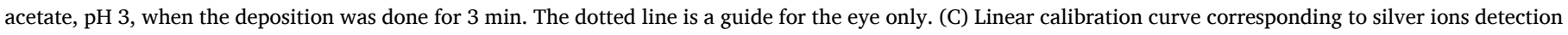
in $0.01 \mathrm{M}$ sodium acetate, $\mathrm{pH} 3$ at a gold working IDA. Deposition time: $4 \mathrm{~min}$ at $-0.2 \mathrm{~V}$. (D) Corresponding stripping peaks.

aliquot of $0.01 \mathrm{M}$ sodium acetate, $\mathrm{pH}$ 3, containing the desired concentration of silver nitrate diluted from a stock solution, was pipetted into the sample well. (b) A bias of $-0.2 \mathrm{~V}$ ( $\mathrm{vs} \mathrm{Ag} / \mathrm{AgCl}$ ) was applied for $3-5$ min to a working IDA to reduce and deposit the silver ions. c) The silver was stripped from the electrode by using SWV undertaken in a positive direction between -0.2 and $0.8 \mathrm{~V}(\mathrm{vs} \mathrm{Ag} / \mathrm{AgCl}$ ) at the following conditions: frequency $15 \mathrm{~Hz}$, increment potential $0.004 \mathrm{~V}$, amplitude $0.025 \mathrm{~V}$, and the silver stripping peak was recorded at $\sim 0.3 \mathrm{~V}$ (vs Ag/ $\mathrm{AgCl})$. d) Following the measurement, the electrode was potientiodynamically cleaned by replacing the sample with $0.01 \mathrm{M}$ sodium acetate solution and applying the potential of $0.5 \mathrm{~V}$ for $150 \mathrm{~s}$, which is a slightly more oxidative potential than observed for silver stripping in sodium acetate. e) SWV was again recorded between -0.2 and $0.8 \mathrm{~V}$ in blank, sodium acetate solution to confirm that all the silver was oxidised from the electrode to prevent carry over from previous experiments.

\subsection{Silver detection method using in-situ $\mathrm{pH}$ control}

For the silver detection using in-situ electrochemical pH control, the same conditions for deposition and stripping as described above were applied, except that $\mathrm{pH}$ of sodium acetate and tap water was not chemically adjusted before (both remained at $\mathrm{pH} \sim 7.5$ ). Instead, a constant oxidising potential was applied to the protonator IDA, to produce protons $\left(\mathrm{H}^{+}\right.$ions) according to Eq. 3, thus tailoring the $\mathrm{pH}$ in the vicinity of the sensor IDA.

$2 \mathrm{H}_{2} \mathrm{O} \rightarrow \mathrm{O}_{2}+4 \mathrm{H}^{+}+4 e^{-}$

During deposition (step b) $1.25 \mathrm{~V}$ (vs $\mathrm{Ag} / \mathrm{AgCl}$ ) or $1.65 \mathrm{~V}$ (vs $\mathrm{Ag} /$ $\mathrm{AgCl})$ was simultaneously applied at the protonator IDA when the measurements were done in $0.01 \mathrm{M}$ sodium acetate and tap water, respectively. During stripping (step c) $1.65 \mathrm{~V}$ (vs Ag/AgCl) was applied to the protonator IDA in $0.01 \mathrm{M}$ sodium acetate and tap water. The oxidation peak was recorded at $\sim 0.3 \mathrm{~V}$ for measurements in sodium acetate while $\sim 0.2 \mathrm{~V}$ for measurements in tap water.

\section{Results and discussion}

\subsection{Sensor Characterisation}

Each chip contained six sensors, comprising two separate microband IDAs, and a gold counter electrode shown in Fig. 2(A). While a platinum pseudo reference electrode was also fabricated on-chip, an external $\mathrm{Ag}$ / $\mathrm{AgCl}$ electrode was used in this work for better stability. A microSD pinout was implemented to allow facile and rapid interconnection with external instrumentation. Each sensor comprised two fully passivated IDAs; the protonator IDA comprised 14 tines while the working IDA comprised 13 tines. The electrochemically active dimensions of each IDA tine were $50 \mathrm{~nm}$ high, $1 \mu \mathrm{m}$ wide, and $45 \mu \mathrm{m}$ long (defined by the width of the passivation window opening) while the gap between the tines in the neighbouring IDAs was $2 \mu \mathrm{m}$. The underlying titanium in the electrode metal stack formed a native oxide layer, when immersed in solution, and was thus electrochemically passivated. Fig. 2(B) shows a sensor chip in a chip holder, prior to insertion into a PCB mounted microSD connector. The well in the centre has a volume of $\sim 500 \mu \mathrm{L}$, sealed onto the chip using an o-ring, and aligned over the on-chip sensor electrodes. As part of the well, there was a space for the external reference electrode, allowing it to maintain in the solution during measurements.

In Fig. 2(C), a typical CV voltammogram obtained using a pristine cleaned gold working IDA is shown. The observed voltammogram 

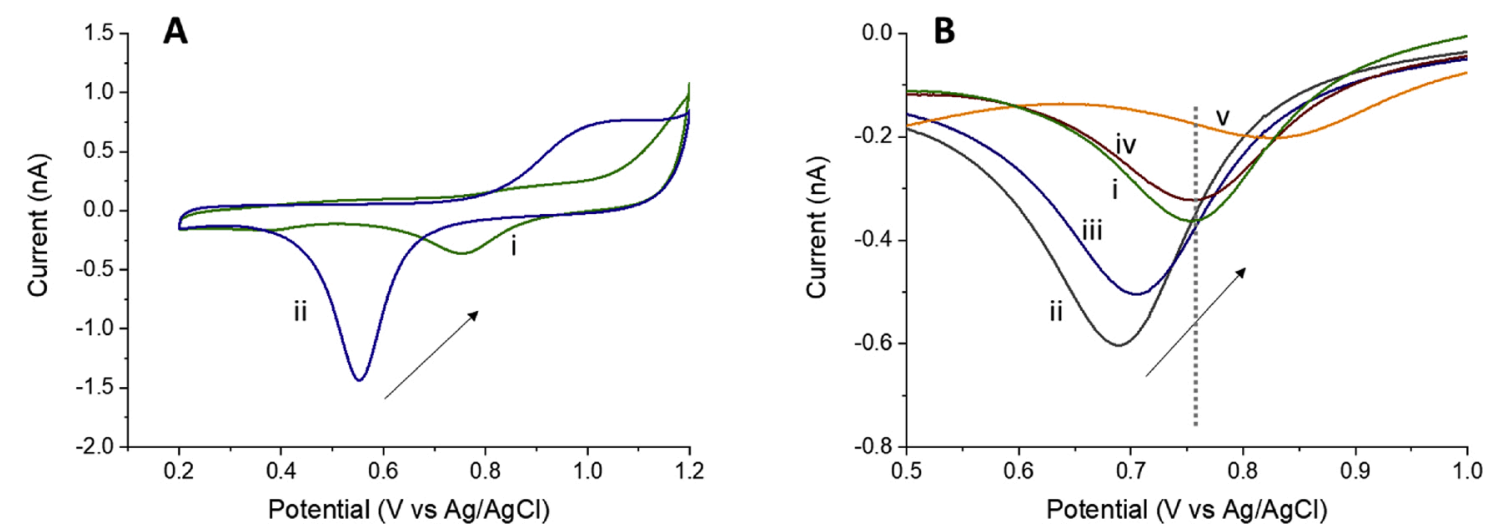

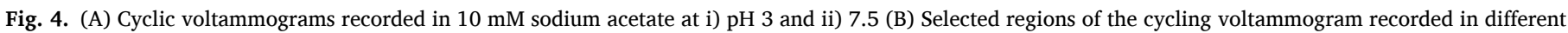

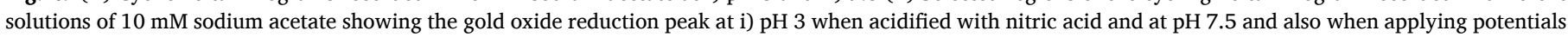

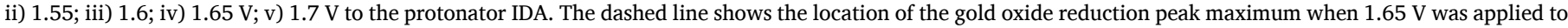
the protonator occurring at the same position as when the solution was acidified to $\mathrm{pH} 3$ with nitric acid.

exhibited a diffusion-limited behaviour consistent with a large microelectrode which arose from the radial diffusion profiles surrounding individual tines of an IDA overlapping, thus resulting in an overall timedependent behaviour [23]. Sensors were then characterised in Generator-Collector mode and a typical voltammogram is presented in Fig. 3(D). In this approach, the generator IDA first oxidised FCA to FCA ${ }^{+}$ species which then diffused across the gap to the collector electrode where it was subsequently reduced back to FCA; establishing redox cycling resulting in higher measured currents. As a result of redox cycling, the Generator-Collector voltammograms exhibited a quasi-steady-state, time independent behaviour typically associated with ultra-microelectrodes [33]. The collection efficiency of the sensor, which is a ratio of the collector to the generator currents, was determined to be $\sim 84 \%$. This thus suggested that $84 \%$ of protons, produced at a protonator IDA, would diffuse to the working IDA, and tailor the $\mathrm{pH}$ as desired.

\subsection{Silver detection optimisation and performance in acidic media}

The influence of the solution $\mathrm{pH}$ on silver deposition was evaluated by varying the buffer $\mathrm{pH}$ between $\mathrm{pH} 2$ and $\mathrm{pH}$ 4.5. $1 \mu \mathrm{M} \mathrm{AgNO}{ }_{3}$ dissolved in $10 \mathrm{mM}$ sodium acetate at different $\mathrm{pH}$ was electrodeposited at a working IDA at $-0.2 \mathrm{~V}$ for $3 \mathrm{~min}$. Following deposition, the silver was then stripped using SWV and the peak current was recorded. In Fig. 3(A), representative stripping current peak heights measured for silver stripping at different $\mathrm{pH}$ are presented. The measurements were undertaken in duplicate for each $\mathrm{pH}$, and the average values with standard deviation were plotted. Decreasing the $\mathrm{pH}$ from 4.5 led to a change in the measured stripping current with the maximum stripping peak current found to be between $\mathrm{pH} 2.5$ and 3.0; $\mathrm{pH} 3$ was thus selected as the $\mathrm{pH}$ of choice for further experiments as the most optimal $\mathrm{pH}$ for silver detection. The corresponding deposition currents are presented in Fig. S2 (A) with a change in deposition current magnitude observed with different $\mathrm{pH}$. Following $\mathrm{pH}$ optimisation, the influence of reduction potential on the peak height was evaluated and optimised. A series of silver electroreduction voltages were assessed by first electro-depositing silver at a selected voltage, followed by a SWV where the peak current was measured. Electro-reduction was undertaken in the voltage range of -0.1 $\mathrm{V}$ and $-0.5 \mathrm{~V}$. It can be seen in Fig. 3(B), a maximum peak current was observed when using a reduction potential of $-0.2 \mathrm{~V}$. Higher currents were measured at more cathodic potentials, this increase arose from the superimposition of an oxygen reduction signal onto the electrodeposition current; see Fig. S2 (B). To this end, $-0.2 \mathrm{~V}$ was selected as the optimal for silver detection and used in further studies.

The deposition time used for silver ions deposition depended on the expected concentration of silver in the solution. In theory, the longer the deposition time, the lower the limit of detection for silver detection can be achieved. However, this must be offset and balanced by an electrode potentially becoming saturated at higher silver concentrations. A series of deposition times were explored. Fig. 3(C) shows the calibration line for silver in $10 \mathrm{mM}$ sodium acetate, $\mathrm{pH} 3$, when the deposition was $4 \mathrm{~min}$ while Fig. 3-(D) shows the corresponding stripping peaks. The linear region was recorded between $0.2-2 \mu \mathrm{M}$. Increasing the deposition time to $5 \mathrm{~min}$ decreased the detection concentration to $0.1 \mu \mathrm{M}$. However, the response became nonlinear above $1 \mu \mathrm{M}$, consistent with an electrode becoming saturated. As a result, the calibration line with 5 min deposition time was between $0.1-1 \mu \mathrm{M}$; see Fig. S3.

\subsection{In-situ electrochemical $p H$ control: potential selection}

As discussed previously, the $\mathrm{pH}$ of the solution greatly influenced the silver deposition process. Electro-generated in-situ $\mathrm{pH}$ control was explored to eliminate the requirement of sample acidification prior to the analysis. First, the potential to be applied at the protonator IDA had to be optimised. It is known that when undertaking cyclic voltammetry at a gold electrode, the positions of the gold oxide and reduction peaks vary, depending on the solution's $\mathrm{pH}$ [34]. In this manner, the voltage at which the gold oxide reduction peak maximum occurs may be used as an indicative measure of the $\mathrm{pH}$ of the solution at a sensor. To confirm this, cyclic voltammetry in $10 \mathrm{mM}$ sodium acetate in the voltage range of $0.2-1.2 \mathrm{~V}$ was performed at $\mathrm{pH} 3$ and $\mathrm{pH} 7.5$ (the selected $\mathrm{pH}$ for silver detection and the $\mathrm{pH}$ of sodium acetate without acidification, respectively). The CVs are presented in Fig. 4 (A). At pH 7.5 the gold oxide reduction peak maximum was observed at $0.55 \mathrm{~V}$. On the addition of nitric acid to acidify the sodium acetate buffer to $\mathrm{pH} 3$, the gold oxide reduction peak moved anodically to $0.76 \mathrm{~V}$, as expected. The decrease in the measured reduction peak area arose from a limited amount of gold oxide formed due to the narrow potential window used; as the gold oxidation process would also have shifted to higher anodic voltages at this lower $\mathrm{pH}$ value.

Fig. 4(B) shows a portion of cyclic voltammograms recorded at the working IDA in $10 \mathrm{mM}$ sodium acetate solution when different potentials (1.55-1.7 V) were applied to the protonator IDA. On increasing the protonator potential, the gold oxide reduction peak was observed to move to higher anodic voltages consistent with a decrease in $\mathrm{pH}$. In these experiments, an applied potential of $1.65 \mathrm{~V}$ yielded a maximum gold reduction peak at $0.76 \mathrm{~V}$; which was the same location as data recorded in acidified sodium acetate $\mathrm{pH} 3$; shown by the dashed line in Fig. 4(B). Although the acetate buffer has a solution pH of 7.5 in the bulk away from the electrode, the local in-situ $\mathrm{pH}$ in the vicinity of the electrode was electrochemically tailored to $\mathrm{pH} 3.0$ using this approach. Thus an applied voltage of $1.65 \mathrm{~V}$ was selected as the protonator voltage 

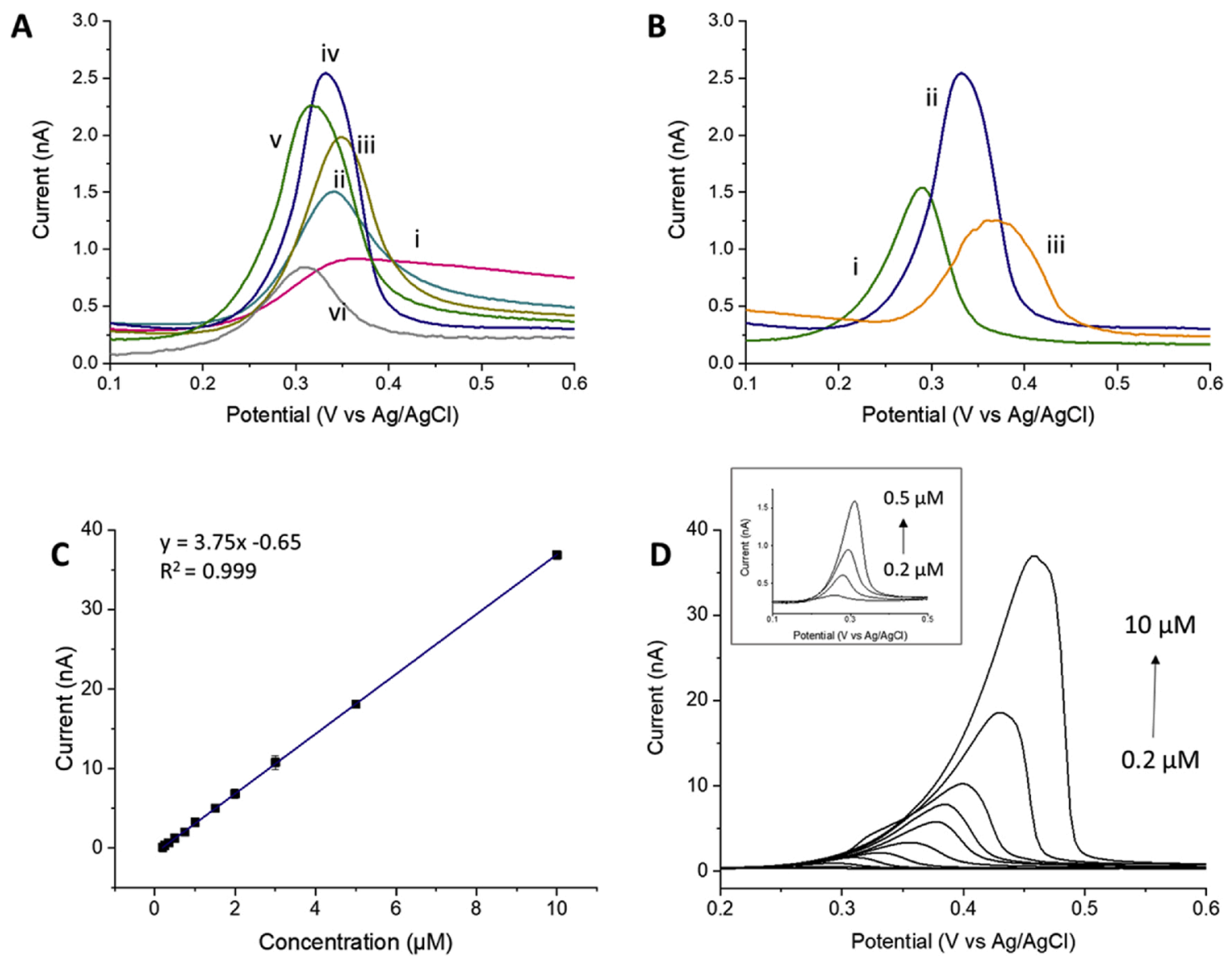

Fig. 5. Square Wave Voltammograms for $1 \mu \mathrm{M}$ of $\mathrm{AgNO}_{3}$ in $10 \mathrm{mM}$ sodium acetate $\mathrm{pH} 7.5$ when (A) i) $1.65 \mathrm{~V}$; ii) $1.45 \mathrm{~V}$; iii) $1.35 \mathrm{~V}$; iv) $1.25 \mathrm{~V}$ v) $1.15 \mathrm{~V}$ and vi) no potential was applied to protonator IDA during silver deposition, while $1.65 \mathrm{~V}$ was applied during stripping (B) $1.25 \mathrm{~V}$ was applied to the protonator IDA during deposition while i) $1.55 \mathrm{~V}$; ii) $1.65 \mathrm{~V}$ and iii) $1.75 \mathrm{~V}$ was applied during stripping. (C) Linear calibration curve corresponding to silver ions detection using pH control. The measurements were done in $10 \mathrm{mM}$ sodium acetate $\mathrm{pH} 7.5$ with $1.25 \mathrm{~V}$ applied at protonator IDA during deposition and 1.65 V during stripping. Deposition time: $3 \mathrm{~min}$ at $-0.2 \mathrm{~V}$. (D) Corresponding stripping peaks. Inset: Stripping peaks for the lowest concentrations.

of choice.

\subsection{Silver detection using in-situ $\mathrm{pH}$ control in acetate buffer}

The initial experiments to assess and optimise in-situ $\mathrm{pH}$ control were undertaken in $10 \mathrm{mM}$ sodium acetate, as described previously. However, as shown in Fig. 5(A), when $1.65 \mathrm{~V}$ was applied to a protonator IDA and a cathodic potential of $-0.2 \mathrm{~V}$ was applied to the working IDA (during silver electrodeposition), the stripping peak for silver was significantly lower when compared to the stripping peak obtained using chemically acidified silver solutions. In addition, the measured current during deposition was significantly higher when using $\mathrm{pH}$ control $(\sim-40 \mathrm{nA}$ at $100 \mathrm{~s}$ ) compared to the deposition current in chemically acidified sodium acetate $(\sim-0.6 \mathrm{nA}$ at $100 \mathrm{~s})$; see Fig. S4. To explain this observation, we believe that this discrepancy may have arisen from competitive parallel electrochemical processes occurring at the sensors electrode in sodium acetate: namely silver electrodeposition and direct oxygen reduction. To explore this further, CVs were undertaken in 0.01 $M$ sodium acetate using pristine gold working IDAs both with and without the protonator IDA biased at $+1.65 \mathrm{~V}$. The corresponding voltammograms are presented in Fig. S5. A significant increase in anodic current was observed at $\sim 1.2 \mathrm{~V}$ without the $\mathrm{pH}$ control and $\sim 1.5 \mathrm{~V}$ when in-situ $\mathrm{pH}$ control (i.e., biasing the protonator) was applied. This current increase corresponds to the formation of a gold oxide layer at the gold working IDA, which is in accordance with the observation of Burke and Nugent [34]. This suggests that setting the protonator IDA to $1.65 \mathrm{~V}$ during silver detection could lead to the production of a significant amount of molecular oxygen. This argument is strongly supported by the significant current increase corresponding to gold oxide reduction at potential $\sim 0.6 \mathrm{~V}$ when $\mathrm{pH}$ control was applied. The cyclic voltammogram in sodium acetate, with applied $\mathrm{pH}$ control, also exhibits an increase of cathodic current starting around $-0.2 \mathrm{~V}$ corresponding to the potential at which the oxygen begins to be reduced in the acidic conditions [35]. Consequently, applying a bias of $1.65 \mathrm{~V}$ to the protonator IDA results in the generation of molecular oxygen which diffuses to and is reduced at a working IDA biased at $-0.2 \mathrm{~V}$. This can explain the observed increase in the magnitude of deposition current (Fig. S4). Concerning analyte mass transfer transport, diffusion of silver ions to a working IDA is diffusion limited, as shown in Fig. 2(C). However, diffusion of oxygen, generated along the entire length of a protonator IDA, to a sensing IDA will be radial in nature and will thus be more efficient. These competitive processes may thus result in the lower concentrations of silver deposited at the working IDA when in-situ $\mathrm{pH}$ control was used compared to the chemically modified solution.

Consequently, a trade-off was required between the applied protonator voltage versus the associated molecular oxygen formation. To this end, $1 \mu \mathrm{M} \mathrm{AgNO}_{3}$ dissolved in $10 \mathrm{mM}$ sodium acetate at $\mathrm{pH} 7.5$ was deposited at the working IDA while different potentials, varying from $1.15 \mathrm{~V}$ to $1.65 \mathrm{~V}$, were applied to the protonator IDA during deposition, followed by SWV, see Fig. 5(A). It was observed that $1.25 \mathrm{~V}$ applied during deposition yielded the maximum stripping peak current and thus was selected for further experiments. The potential applied to a protonator IDA during stripping of silver electrodeposited at the working IDA was also optimised. It can be seen in Fig. 5(B) that resetting the protonator voltage back to $1.65 \mathrm{~V}$ during SWV resulted in the highest stripping peak. This further supports the hypothesis that molecular oxygen 

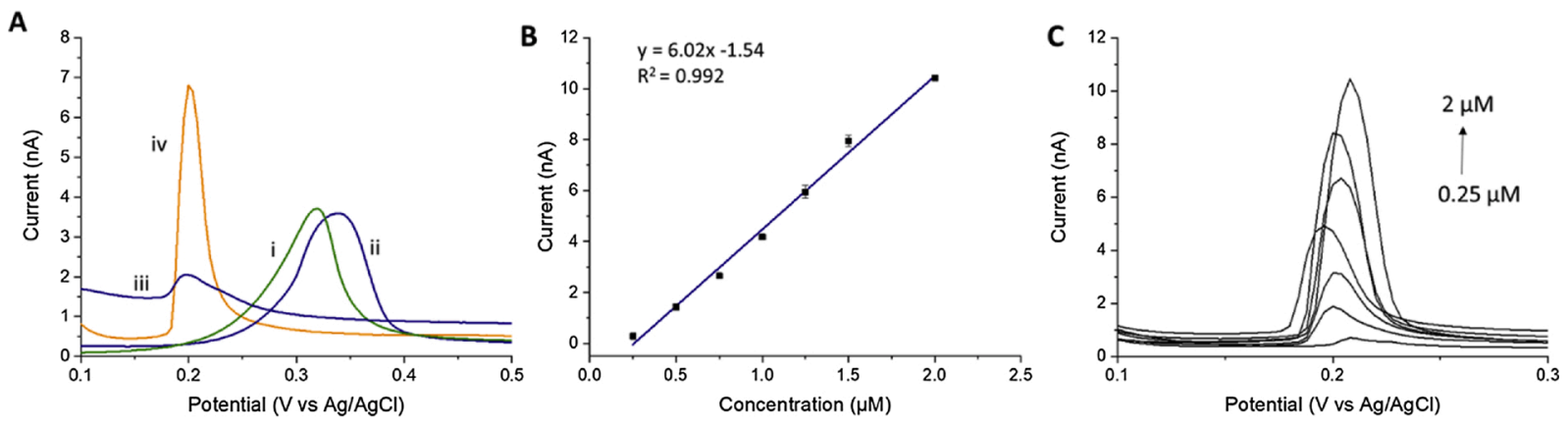

Fig. 6. (A) Square Wave Voltammograms of $1 \mu \mathrm{M} \mathrm{AgNO}_{3}$ in i) $10 \mathrm{mM}$ sodium acetate $\mathrm{pH} 3$; ii) $10 \mathrm{mM}$ sodium acetate at $\mathrm{pH} 7.5$ when $\mathrm{pH}$ control was applied (1.25 V at the protonator IDA during deposition and $1.65 \mathrm{~V}$ during stripping); iii) tap water at $\mathrm{pH} 7$; iv) tap water when $\mathrm{pH}$ was applied (1.65 $\mathrm{V}$ at the protonator IDA during deposition and stripping). Conditions for the experiment were: deposition at $-0.2 \mathrm{~V}$ for $3 \mathrm{~min}$. (B) Linear calibration curve corresponding to silver ions detection in tap water. Conditions for the experiment were: deposition at $-0.2 \mathrm{~V}$ for $2 \mathrm{~min}, 1.65 \mathrm{~V}$ at protonator IDA during deposition, and stripping. (C) Corresponding stripping peaks.

formation was an interferent during deposition but not during the stripping process due to the more anodic applied anodic potentials (too positive to enable oxygen reduction).

A silver detection calibration was then undertaken in the concentration range from $0.2-10 \mu \mathrm{M}(10 \mathrm{mM}$ sodium acetate, deposition time: three min) using the in-situ electro-generated $\mathrm{pH}$ control method and the resulting plot is presented in Fig. 5(C). The data points represent the mean value of three replicate measurements, with the error bars representing one standard deviation. The calibration curve exhibited excellent linearity with $\mathrm{R}^{2}$ of 0.999 and a wide linear dynamic range of $0.2-10 \mu \mathrm{M}$ with the lowest limit of detection (LOD) of $13 \mathrm{nM}$, calculated using the equation:

$L O D=3.3 \times S D \div s$

Where SD is the standard deviation of the blank solution and $s$ is the slope. These results highlight the suitability of the proposed approach for the electrochemical detection of silver using in-situ pH control. Fig. 5 (D) shows the corresponding stripping voltammograms for the different concentrations and a clear anodic shift of the stripping peak with increased concentration of silver was noted. Fig. 5(D): inset shows the stripping peaks in the lowest concentrations $(0.2-0.5 \mu \mathrm{M})$ for their better evaluation. A similar potential shift in detection of silver ions was reported in a previous study [16] and it can be explained with the Nernst equation where, with increased concentration of $\mathrm{Ag}$ ions, the equilibrium potential of $\mathrm{Ag} / \mathrm{Ag}+$ increase. The potential was stable for triplicate measurements at the same concentration, see Fig. S6.

\subsection{Silver detection using in-situ $\mathrm{pH}$ control in tap water}

Having shown a proof of concept of silver detection using in-situ $\mathrm{pH}$ control in sodium acetate as described above, the developed method was applied and optimised for potable tap water. Typically, the $\mathrm{pH}$ of drinking water varies between 6.5-8.5 [36] and may need to be adjusted and optimised before silver detection, i.e., $\mathrm{pH} 3$. A CV was undertaken in tap water with $1.65 \mathrm{~V}$ applied to the protonator IDA; see Fig. S7. It was observed that oxygen reduction in tap water requires a more cathodic potential $(\sim-0.5 \mathrm{~V})$ compared to sodium acetate $(\sim-0.2 \mathrm{~V})$ which suggested that the competitive process, described above, should not significantly interfere with silver deposition. To this end, in-situ $\mathrm{pH}$ control was undertaken by applying the desired $1.65 \mathrm{~V}$ to the protonator during both the silver deposition and stripping steps.

Tap water was spiked with $1 \mu \mathrm{M} \mathrm{AgNO}_{3}$ as silver was not present at detectable levels in water in our lab, which was confirmed with water analysis. No additional supporting electrolyte was added to the test to verify that the sensor could be used for real time tap water detection. Fig. 6(A) shows the square wave voltammograms in tap water, both with and without $\mathrm{pH}$ control. We note that the silver stripping peaks shifted to more cathodic values, and the peaks became higher and sharper when compared to measurements undertaken in sodium acetate buffer (the silver stripping peaks measured in sodium acetate with and without $\mathrm{pH}$ control are included in Fig. 6(A) for comparison). The cathodic shift and change in the voltammetric profile can likely be attributed to the presence of chloride ions due to the disinfection of tap water with chlorine. Therefore, the stripping peak in tap water corresponded to an $\mathrm{AgCl}^{-}$ complex, instead of $\mathrm{Ag}^{+}$ion as detected in sodium acetate, following the mechanism previously described by Saterlay et al. [30]. In their work the process of a peak sharpening upon complexation of silver with chloride was used for its beneficial analytical applications, with $\mathrm{KCl}$ added to the sample after optimisation, following the equations:

$\mathrm{Ag}_{(s)}+\mathrm{Cl}^{-} \leftrightarrow \mathrm{AgCl}_{(s)}+e^{-}$

$\mathrm{AgCl}_{(s)}+\mathrm{Cl}^{-} \leftrightarrow \mathrm{AgCl}_{2(a q)}^{-}$

$\mathrm{AgCl}_{2(a q)}^{-} \rightarrow$ bulk solution

In this work, chlorine was naturally present in excess in tap water due to the chlorination, which is the most commonly used water disinfection process in Ireland and worldwide $[37,38]$. These results show that the $\mathrm{pH}$ control approach works for both silver ions and silver complexes. Thus, no additional reagent had to be added to enhance silver detection. Regardless of the form of chlorine used (gaseous chlorine, calcium hypochlorite or sodium hypochlorite), a combination of hypochlorous acid $(\mathrm{HOCl})$ and hypochlorite ion $\left(\mathrm{OCl}^{-}\right)$will be present in tap water as "free available chlorine" at levels between $0.2 \mathrm{~g} / \mathrm{L}$ and 1 $\mathrm{mg} / \mathrm{L}$ to assure the safety of water $[5,39]$.

Since the measured silver species changed from an $\mathrm{Ag}^{+}$ion to $\mathrm{AgCl}$ complex, an additional calibration line was established for tap water. First it was observed that a deposition time of three minutes (as used previously) resulted in an electrode becoming saturated with silver chloride at concentrations above $1 \mu \mathrm{M}$ of $\mathrm{AgNO}_{3}$. For this reason, the deposition time was reduced to two minutes. This resulted in both a wider linear dynamic range and provided a faster time to result. A linear calibration plot for silver detection in tap water, using in-situ electrogenerated $\mathrm{pH}$ control, was found between 0.25 and $2 \mu \mathrm{M}$, see Fig. 6(B) and the LOD was found to be $106 \mathrm{nM}$. The data points represent the mean value of three replicate measurements, with the error bars representing 1 standard deviation. The calibration curve exhibited excellent linearity with $\mathrm{R}^{2}$ of 0.992 . The corresponding stripping peaks are presented on Fig. 6(C) and it is important to highlight that the peak did not move with increased silver concentration as expected. According to Nernst equation, in this case the peak potential depends just on chloride concentration $[40,41]$. Considering that in our experiments chloride concentration is constant, the peak potential remains in the same position. This confirms our thesis that the reaction detected in tap water is 
Table 1

Comparison of silver detection studies using anodic sweep voltammetry.

\begin{tabular}{|c|c|c|c|c|c|c|c|}
\hline Electrode & Linear Range $\mu \mathrm{M}$ & Sensitivity $\mathrm{mA} \mu \mathrm{M}^{-1} \mathrm{~cm}^{-2}$ & LOD nM & Solution $\mathrm{pH}$ & Deposition time s & Real samples & Ref. \\
\hline $\mathrm{Au}-\mathrm{SC}$ & $0.0005-1000$ & 0.0000465 & 0.02 & - & - & Tap, river water & [42] \\
\hline Pt-PTH & $0.649-9.27$ & 0.282 & 556 & 5 & $120(\mathrm{R})$ & Waste water & [43] \\
\hline GaN MPE & $0.092-9.27$ & 0.113 & 30.6 & 5.2 & $180(\mathrm{R})$ & Tap water & [16] \\
\hline BDD & $\begin{array}{l}\left.1-7 \text { (with } \mathrm{SO}_{4}^{2-}\right) \\
0.01-0.08\left(\mathrm{no} \mathrm{SO}_{4}^{2-}\right)\end{array}$ & 0.00021 (with $\left.\mathrm{SO}_{4}^{2-}\right) 8.736\left(\right.$ no $\left.\mathrm{SO}_{4}^{2-}\right)$ & 0.2 & 5.2 & $240(\mathrm{R})$ & Soap water & [15] \\
\hline GCE-TCA & $0.05-3$ & 0.0167 & 10 & 4.5 & $\begin{array}{l}1200(\mathrm{~A}) \\
30(\mathrm{R})\end{array}$ & Tap, lake, lynthesized water & [44] \\
\hline GCE-ABP & $0.05-1$ & 0.548 & 25 & 5.2 & $180(\mathrm{R})$ & Tap, river water & [32] \\
\hline СРE-2-НBBH & $0.0000093-0.00037$ & 0.863 & 0.0093 & $\begin{array}{l}5.5 \\
1 \text { (real samples) }\end{array}$ & $\begin{array}{l}180(\mathrm{~A}) \\
180(\mathrm{R})\end{array}$ & River water & [18] \\
\hline NBHAE-MCPE & $0.0046-1.85$ & 1.787 & 0.85 & 9.5 & $\begin{array}{l}540(\mathrm{~A}) \\
20(\mathrm{R})\end{array}$ & $\mathrm{X}$-ray films, water samples & [19] \\
\hline NanoAg-MWCNTs-MCPE & $0.0005-0.28$ & 4.97 & 0.12 & $\begin{array}{l}5 \\
2 \text { (real samples) }\end{array}$ & $180(\mathrm{R})$ & Tap, river, ground water & [45] \\
\hline $\begin{array}{l}\text { Au-IDA (sodium } \\
\text { acetate) }\end{array}$ & $0.2-10$ & 0.641 & 13 & $7.5+\mathrm{pH}$ control & $180(\mathrm{R})$ & & \\
\hline $\begin{array}{l}\text { Au-IDA } \\
\quad \text { (tap water) }\end{array}$ & $0.25-2$ & 1.029 & 106 & $7.5+\mathrm{pH}$ control & $120(\mathrm{R})$ & Tap water & This work \\
\hline
\end{tabular}

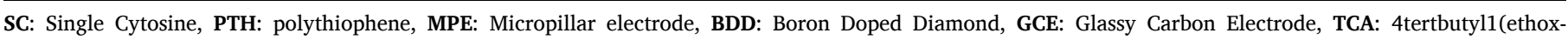

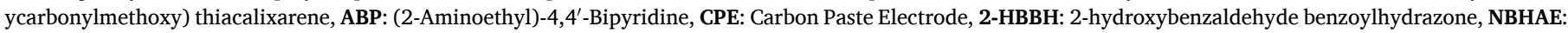

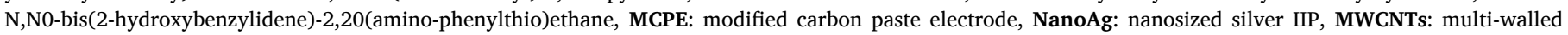
carbon nanotubes, IDA: interdigitated microelectrode array, A: accumulation, R: reduction.

the oxidation of silver to silver chloride.

Table 1 summarises other studies describing detection of silver ions in aqueous samples using ASV. Although several authors have reported electrochemical approaches for silver detection in tap water, most of these reports had to (i) modify the working electrode, (ii) first acidify the solution using an acid $[10,18]$ and/or (iii) add additional electrolyte before performing the measurements $[19,20]$ to obtain optimal $\mathrm{pH}$ for silver detection. To the best of our knowledge, none of these papers have reported silver detection using in-situ $\mathrm{pH}$ control. Moreover, our sensor exhibited excellent sensitivity comparable to other authors, which was even improved with aid of chlorine in tap water with only 2 min of deposition time. We believe that the LOD could be further decreased if the electrode was modified or time of deposition increased. The limitation of the presented study is a need for the optimisation of the potential applied to the generator electrode, depending on the matrix of the sample as the potential at which the oxygen is reduced may vary. Our results have suggested that silver detection efficiency was improved with the chloride ions present in tap water. Based on Saterlay et al. [30] the intensity of the $\mathrm{AgCl}$ peak will depend on the concentration of chloride in the water, which they have shown by undertaking measurements with different concentrations of $\mathrm{KCl}$. This suggests that the concentration of chlorine in the tap water could be another limiting factor for the presented technique. Based on WHO guidelines, chlorine is present in most disinfected tap water at a concentration between 0.2 $\mathrm{mg} / \mathrm{L}$ and $1 \mathrm{mg} / \mathrm{L}$ [5]. This means there should be a sufficient amount of chlorine present to allow the detection of the target silver concentrations $(0.1 \mathrm{mg} / \mathrm{L})$. Using this approach and the sensors developed herein, silver detection may be undertaken in previously chlorinated tap water without the addition of electrolyte, acid, or base when a prior calibration is done. If insufficient concentration of chlorine was present $(<0.1$ $\mathrm{mg} / \mathrm{L}$ ) in solution, the additional chloride salt may need to be added.

\section{Conclusions}

We present an easy and quick technique that employs interdigitated electrodes for silver detection in sodium acetate and tap water using an electro-generated in-situ $\mathrm{pH}$ control method. Silver detection was undertaken using square wave voltammetry at a working IDA with simultaneous production of hydrogen ions at a protonator IDA which allowed the $\mathrm{pH}$ to be tailored in the vicinity of the sensor. In addition, the complexation of the silver ions with chlorine present in tap water enabled more sensitive detection and faster time-to-result with no addition of electrolytes. The sensors have the potential to be directly deployed for real time detection in water utility systems as well as in estuarine or marine waters, without the need for preconditioning of a sample. There might be a need for adding chloride salt prior to measurement if other than chlorination disinfection process was used as well as optimising the potential applied at the protonator IDA according to the sample matrix.

\section{CRediT authorship contribution statement}

Luiza A. Wasiewska: Investigation, Writing - original draft, Visualization, Data curation. Ian Seymour: Methodology, Formal analysis. Bernardo Patella: Methodology, Writing - review \& editing. Rosalinda Inguanta: Supervision. Catherine M. Burgess: Writing - review \& editing, Supervision, Funding acquisition. Geraldine Duffy: Writing review \& editing, Supervision, Funding acquisition. Alan O'Riordan: Writing - review \& editing, Conceptualization, Supervision, Funding acquisition.

\section{Declaration of Competing Interest}

The authors declare that they have no known competing financial interests or personal relationships that could have appeared to influence the work reported in this paper.

\section{Acknowledgements}

This study was funded in part by the Teagasc Walsh Scholarship Scheme (Ref: 2016024) and has emanated in part from research conducted with the financial support of Science Foundation Ireland (SFI) and the Department of Agriculture, Food and Marine on behalf of the Government of Ireland under Grant Number [16/RC/3835] VistaMilk.

\section{Appendix A. Supplementary data}

Supplementary material related to this article can be found, in the online version, at doi:https://doi.org/10.1016/j.snb.2021.129531. 


\section{References}

[1] G. Oberdörster, V. Stone, K. Donaldson, Toxicology of nanoparticles: a historical perspective, Nanotoxicology 1 (1) (2007) 2-25.

[2] R. Behra, L. Sigg, M.J. Clift, F. Herzog, M. Minghetti, B. Johnston, et al., Bioavailability of silver nanoparticles and ions: from a chemical and biochemical perspective, J. R. Soc. Interface 10 (87) (2013) 20130396.

[3] S.-j. Yu, Y.-g. Yin, J.-f. Liu, Silver nanoparticles in the environment, Environ. Sci. Process. Impacts 15 (1) (2013) 78-92.

[4] K.D. Rosenman, A. Moss, S. Kon, Argyria: clinical implications of exposure to silver nitrate and silver oxide, J. Occup. Med. 21 (6) (1979) 430-435.

[5] WHO, Guidelines for Drinking-water Quality, 4th Edition, Incorporating the 1st Addendum, World Health Organization, Geneva, 2017, p. 564. https://www.who. int/publications/i/item/9789241549950.

[6] US EPA, Edition of the Drinking Water Standards and Health Advisories Tables 2018, United States Environmental Protection Agency, Washington, DC, 2018. https://www.epa.gov/sites/production/files/2018-03/documents/dwtable 2018.pdf.

[7] M. Karimi, S. Mohammadi, A. Mohadesi, A. Hatefi-Mehrjardi, M. MazloumArdakani, L.S. Korani, et al., Determination of silver (I) by flame atomic absorption spectrometry after separation/preconcentration using modified magnetite nanoparticles, Sci. Iran. 18 (3) (2011) 790-796.

[8] Z. Gao, G.G. Liu, H. Ye, R. Rauschendorfer, D. Tang, X. Xia, Facile colorimetric detection of silver ions with picomolar sensitivity, Anal. Chem. 89 (6) (2017) 3622-3629.

[9] T. Anand, G. Sivaraman, P. Anandh, D. Chellappa, S. Govindarajan, Colorimetric and turn-on fluorescence detection of Ag (I) ion, Tetrahedron Lett. 55 (3) (2014) 671-675.

[10] A. Afkhami, A. Shirzadmehr, T. Madrakian, H. Bagheri, New nano-composite potentiometric sensor composed of graphene nanosheets/thionine/molecular wire for nanomolar detection of silver ion in various real samples, Talanta 131 (2015) $548-555$.

[11] A. Waheed, M. Mansha, N. Ullah, Nanomaterials-based electrochemical detection of heavy metals in water: current status, challenges and future direction, TrAC Trends Anal. Chem. 105 (2018) 37-51.

[12] C. Barrett, K. Dawson, C. O'Mahony, A. O'Riordan, Development of low cost rapid fabrication of sharp polymer microneedles for in vivo glucose biosensing applications, ECS J. Solid State Sci. Technol. 4 (10) (2015) S3053-S3058.

[13] K. Dawson, A. Wahl, S. Barry, C. Barrett, N. Sassiat, A.J. Quinn, et al., Fully integrated on-chip nano-electrochemical devices for electroanalytical applications, Electrochim. Acta 115 (2014) 239-246.

[14] B. Patella, R. Inguanta, S. Piazza, C. Sunseri, Nanowire ordered arrays for electrochemical sensing of H2O2, Chem. Eng. Trans. 47 (2016) 19-24.

[15] E. Culková, Z. Lukáčová-Chomisteková, R. Bellová, D. Melicherčíková, J. Durdiak, M. Rievaj, et al., Voltammetric detection of silver in commercial products on boron doped diamond electrode: stripping at lowered potential in the presence of thiosulfate ions, Monatshefte für Chemie-Chemical Monthly (2020) 1-9.

[16] Q. Liu, J. Li, W. Yang, X. Zhang, C. Zhang, C. Labbé, et al., Simultaneous detection of trace $\mathrm{Ag}$ (I) and $\mathrm{Cu}$ (II) ions using homoepitaxially grown GaN micropillar electrode, Anal. Chim. Acta 1100 (2020) 22-30.

[17] T.J. Davies, Anodic stripping voltammetry with graphite felt electrodes for the trace analysis of silver, Analyst 141 (15) (2016) 4742-4748.

[18] H. El-Mai, E. Espada-Bellido, M. Stitou, M. García-Vargas, M.D. Galindo-Riaño, Determination of ultra-trace amounts of silver in water by differential pulse anodic stripping voltammetry using a new modified carbon paste electrode, Talanta 151 (2016) 14-22.

[19] H.H. Nadiki, M.A. Taher, H. Ashkenani, I. Sheikhshoai, Fabrication of a new multiwalled carbon nanotube paste electrode for stripping voltammetric determination of Ag (I), Analyst 137 (10) (2012) 2431-2436.

[20] S. Jahandari, M.A. Taher, H. Fazelirad, I. Sheikhshoai, Anodic stripping voltammetry of silver (I) using a carbon paste electrode modified with multi-walled carbon nanotubes, Microchimica Acta 180 (5-6) (2013) 347-354.

[21] M. Javanbakht, F. Divsar, A. Badiei, F. Fatollahi, Y. Khaniani, M.R. Ganjali, et al, Determination of picomolar silver concentrations by differential pulse anodic stripping voltammetry at a carbon paste electrode modified with phenylthioureafunctionalized high ordered nanoporous silica gel, Electrochim. Acta 54 (23) (2009) 5381-5386.

[22] S.X. Guo, S.B. Khoo, Highly selective and sensitive determination of silver (I) at a poly (8-mercaptoquinoline) film modified glassy carbon electrode, Electroanalysis 11 (12) (1999) 891-898.

[23] A. Wahl, S. Barry, K. Dawson, J. MacHale, A. Quinn, A. O'Riordan, Electroanalysis at ultramicro and nanoscale electrodes: a comparative study, J. Electrochem. Soc. 161 (2) (2014) B3055-B3060.

[24] K. Dawson, A.L. Wahl, R. Murphy, A. O'Riordan, Electroanalysis at single gold nanowire electrodes, J. Phys. Chem. C 116 (27) (2012) 14665-14673.

[25] P. Sidambaram, J. Colleran, Nanomole silver detection in Chloride-Free phosphate buffer using platinum and gold Micro- and nanoelectrodes, J. Electrochem. Soc. 166 (6) (2019) B532-B541.

[26] Y. Zhang, G.M. Zeng, L. Tang, J. Chen, Y. Zhu, X.X. He, et al., Electrochemical sensor based on electrodeposited graphene-Au modified electrode and nanoAu carrier amplified signal strategy for attomolar mercury detection, Anal. Chem. 87 (2) (2015) 989-996.

[27] A. Zeng, E. Liu, S. Tan, S. Zhang, J. Gao, Stripping voltammetric analysis of heavy metals at nitrogen doped diamond-like carbon film electrodes, Electroanalysis 14 (18) (2002) 1294-1298.
[28] B. Patella, C. Sunseri, R. Inguanta, Nanostructured based electrochemical sensors, J. Nanosci. Nanotechnol. 19 (6) (2019) 3459-3470.

[29] T.L. Read, E. Bitziou, M.B. Joseph, J.V. Macpherson, In situ control of local pH using a boron doped diamond ring disk electrode: optimizing heavy metal (mercury) detection, Anal. Chem. 86 (1) (2014) 367-371.

[30] A.J. Saterlay, F. Marken, J.S. Foord, R.G. Compton, Sonoelectrochemical investigation of silver analysis at a highly boron-doped diamond electrode, Talanta 53 (2) (2000) 403-415.

[31] A. Mohadesi, M.A. Taher, Stripping voltammetric determination of silver (I) at carbon paste electrode modified with 3-amino-2-mercapto quinazolin-4 (3H)-one, Talanta 71 (2) (2007) 615-619.

[32] M.-C. Radulescu, A. Chira, M. Radulescu, B. Bucur, M.P. Bucur, G.L. Radu, Determination of silver (i) by differential pulse voltammetry using a glassy carbon electrode modified with synthesized N-(2-Aminoethyl)-4, 4'-Bipyridine, Sensors 10 (12) (2010) 11340-11351.

[33] A.J. Wahl, I.P. Seymour, M. Moore, P. Lovera, A. O'Riordan, J.F. Rohan, Diffusion profile simulations and enhanced iron sensing in generator-collector mode at interdigitated nanowire electrode arrays, Electrochim. Acta 277 (2018) 235-243.

[34] L. Burke, P. Nugent, The electrochemistry of gold: I the redox behaviour of the metal in aqueous media, Gold Bull. 30 (2) (1997) 43-53.

[35] N. Alexeyeva, T. Laaksonen, K. Kontturi, F. Mirkhalaf, D.J. Schiffrin, K. Tammeveski, Oxygen reduction on gold nanoparticle/multi-walled carbon nanotubes modified glassy carbon electrodes in acid solution, Electrochem. Commun. 8 (9) (2006) 1475-1480.

[36] WHO, pH in Drinking-water. Revised Background Document for Development of WHO Guidelines for Drinking-water Quality, World Health Organization, 2007. htt ps://www.who.int/water sanitation health/dwq/chemicals/ph revised 2007 clea n_version.pdf.

[37] J.G. Jacangelo, R.R. Trussell, International report: water and wastewater disinfection-trends, issues and practices, Water Sci. Technol. Water Supply 2 (3) (2002) 147-157.

[38] EPA Ireland, The Provision and Quality of Drinking Water in Ireland. A Report for the Year, 2011, Environmental Protection Agency, Wexford, 2010, p. 126, https: //www.epa.ie/pubs/reports/water/drinking/drinkingwaterreport2010.html.

[39] I. Seymour, B. O'Sullivan, P. Lovera, J.F. Rohan, A. O'Riordan, Electrochemical detection of free-chlorine in water samples facilitated by in-situ $\mathrm{pH}$ control using interdigitated microelectrodes, Sens. Actuators B Chem. 325 (2020) 128774.

[40] F. Pargar, H. Kolev, D.A. Koleva, K. van Breugel, Potentiometric response of Ag/ $\mathrm{AgCl}$ chloride sensors in model alkaline medium, Adv. Mater. Sci. Eng. 2018 (2018).

[41] D. Tao, L. Jiang, M. Jin, A method of preparation of Ag/AgCl chloride selective electrode, J. Wuhan Univ. Technol. Sci. Ed. 33 (4) (2018) 767-771.

[42] J.H. Kim, K.B. Kim, J.S. Park, N. Min, Single cytosine-based electrochemical biosensor for low-cost detection of silver ions, Sens. Actuators B Chem. 245 (2017) 741-746.

[43] H. Zejli, J.H.-H. de Cisneros, I. Naranjo-Rodriguez, K. Temsamani, Stripping voltammetry of silver ions at polythiophene-modified platinum electrodes, Talanta 71 (4) (2007) 1594-1598.

[44] F. Wang, C. Xin, Y. Wu, Y. Gao, B. Ye, Anodic stripping voltammetric determination of silver (I) in water using a 4-tert-butyl-1 (ethoxycarbonylmethoxy) thiacalix [4] arene modified glassy carbon electrode, J. Anal. Chem. 66 (1) (2011) $60-65$.

[45] R. Zhiani, M. Ghanei-Motlag, I. Razavipanah, Selective voltammetric sensor for nanomolar detection of silver ions using carbon paste electrode modified with novel nanosized Ag (I)-imprinted polymer, J. Mol. Liq. 219 (2016) 554-560.

Luiza Wasiewska graduated from the Wageningen University with a Master's Degree in Food Safety. Currently is pursuing PhD degree between Teagasc Food Research Centre Ashtown in Dublin and Tyndall National Institute in Cork, Ireland. Her research focuses on developing electrochemical sensors for food safety applications. Her PhD project focuses on detection of Verocytotoxigenic E. coli (VTEC) using electrochemistry.

Ian Seymour is studying for a PhD degree at Tyndall National Institute in Cork, Ireland. His research consists of developing electrochemical sensors using dual electrode set-up for environmental analysis applications.

Bernardo Patella obtained his master degree in Chemical Engineering in 2015 from the University of Palermo, Italy. He received the PhD degree in 2019 from the University of Catania. Currently, he is a Postdoctoral Researcher at the University of Palermo, Department of Engineering. His research interests include the development of nanostructured electrochemical sensors for environmental, food, pharmaceutical, biochemical and industrial control.

Rosalinda Inguanta is currently associate professor in Applied Physical Chemistry at the University of Palermo, Department of Engineering. She received the PhD degree in 2008 from the University of Palermo. Her research interests include the synthesis of nanostructured electrochemical devices for electrochemical sensors, batteries, solar cells and electrolysers, synthesis of bio-coatings to prevent the corrosion of medical devices in human body and the recovery of precious metals from electronic waste.

Catherine (Kaye) Burgess graduated with her PhD from University College Cork in 2005. She is a Senior Research Officer in the Food Safety Department in Teagasc Research Centre Ashtown in Dublin. Kaye's research focus is on understanding the behaviour and virulence of foodborne pathogens and antimicrobial resistant microorganisms along the farm to fork 
chain. She currently coordinates and participates in a number of FIRM, EPA and Teagasc funded projects and was a work group leader on the recently completed EU FP7 project AQUAVALENS, which focused on detection of pathogens in water used in food production.

Geraldine Duffy received her PhD from the University of Ulster in 1994. She is a Senior Principal Research Officer and Head of the Food Safety Department at Teagasc Research Centre, Ashtown, Dublin. Her research focuses on the detection, transmission and control of microbial pathogens, along the farm to fork chain. Her research has had a particular focus on Shigatoxigenic E. coli (STEC) in food production animals and red meat.
Alan O'Riordan received his PhD in 2005, from the University College Cork. He is a Senior Research Fellow at the Tyndall National Institute and the Principal Investigator for Smart Agri-food and Nanosensors \& Systems. He coordinates/partners in a portfolio of National and EU projects and his research focuses on using nanomaterials \& nanofabrication to develop end-to-end highly functional smart sensor systems, based on Raman spectroscopy and nanoelectrochemistry. 